\title{
Investigation of Soft Soil Subway Tunnel Subsidence Based on Multiple Factors
}

\author{
Li Guihua \\ School of Earth Science and Engineering \\ Hohai University \\ Nanjing, China \\ lgh82911@hhu.edu.cn \\ Tang Wei \\ School of Earth Science and Engineering \\ Hohai University \\ Nanjing, China \\ 604543874@qq.com
}

\author{
Zhao Bingshuai \\ School of Earth Science and Engineering \\ Hohai University \\ Nanjing, China \\ 645987683@qq.com \\ Guo Xiantao \\ School of Earth Science and Engineering \\ Hohai University \\ Nanjing, China \\ 627791396@qq.com
}

\begin{abstract}
Objective: the subsidence of soft soil subway tunnel structure is a key threat to the safe operation of subway system. In order to detect and respond the problems timely, it is necessary to constantly monitor the subsidence of soft soil subway tunnel structure and to analyze its variation over time. Methods: a subway tunnel is buried in the ground and is usually in operation all the time, making it difficult to use common methods of monitoring the deformation of the tunnel structure. This difficulty can be overcome by deploying sensors. In this study, based on the characteristics of soft soil subway tunnel subsidence, data of various influencing factors have been monitored. According to the principal component analysis and the qualitative analysis of different factors, a mathematical relationship was derived between each influencing factor and soft soil subway tunnel subsidence. By applying principal component analysis from both time and space, the degree of influence of each factor was analyzed both qualitatively and quantitatively. Results: the results accurately showed the influence of different factors in the process of subway tunnel subsidence. Conclusion: this study shows that the use of sensors could be a practical and effective method to monitor the settlement of soft soil subway tunnel.
\end{abstract}

Keywords- subway tunnel; subsidence; multiple factors; soft soil; principal component analysis

\section{INTRODUCTION}

The adverse conditions of the subway tunnel in soft soil, such as stratum geological environment, complex engineering characteristics and significant spatial variation of soil distribution, have posed a serious threat to the settlement of tunnel structure [1-3]. At the same time, some other factors, such as the external environmental influence, the change of the load and other unforeseen causes, have increased the complexity of the tunnel structure settlement. Therefore, identification of the cause of the subway tunnel settlement in the soft soil, and analysis of the qualitative and quantitative extent of the settlement caused by different influencing factors are the key drivers to research the settlement of subway tunnel in soft soil.

At present, the subway tunnel settlement monitoring mechanisms during the operation period are not perfect enough, with limited capability to meet the demand of practicability, reliability and accuracy of the settlement monitoring. Also, it is difficult to meet the long-term demand during the operation of subway tunnel settlement monitoring. As a result, it is urgent to find new research means and methods. This study used a variety of relevant monitoring information as fundamental factors, analyzed the degree of influence of the factors, and studied the subway tunnel settlement cause during the operation period.

\section{ANALYSiS OF THE CAUSE OF Soft SOIL SUbWAY TUNNEL SUBSIDENCE}

According to the structural characteristics and settling characteristics of subway tunnel in soft soil, the factors influencing the settlement of subway tunnel structure in service period are divided into four categories as, environment factors of soil, tunnel structure factors, train load factors and factors of external environment load [4-7]. The environment factors of soil includes geological factors and factors about the variation in groundwater level; the tunnel structure factor is mainly the leakage in tunnels caused by cracking; the train load factors include train traffic and passenger volume; and the factors of external environment load mainly consist of building load, traffic load, regional land subsidence, and regional atmospheric precipitation on the ground area above the tunnel.

\section{A. Soil Environmental Factor}

Soft soil is characterized by low strength, variable thickness and complex characteristics of consolidation and creep. Also, a large difference exists between the vertical and the horizontal permeability. The soil environmental factors can be grouped into two categories, namely, geological factors and the underground water level change. The geological factors can be further divided as, the tunnel 
under the bottom of the soil distribution, and the aging (soil consolidation and creep) characteristics. On the other hand, the underground water level factor represents the soil subsidence caused by the variation in groundwater level.

\section{1) Geological Factor}

a) Effect of the substratum soil layer distribution on the baseboard of a tunnel

When the substratum soil layer distribution on the baseboard of a tunnel is thick, the tunnel experiences a large settlement, and vice versa. Therefore, the thickness of soft soil layer directly affects the settlement stability of the longitudinal subway structure. Based on the layer-wise summation method, the foundation settlement for unidirectional compression is given by the formula[8]:

$$
S=\sum_{i=1}^{n} \Delta S_{i}=\sum_{i=1}^{n} \frac{\Delta p_{i}}{E_{S i}} \cdot H_{i}
$$

where $i$ is the number of thin compressed soil layers from 1 to $\mathrm{n} ; H$ is the thickness of the layer; $\Delta p$ is the average additional stress on the layer; and $E_{S}$ is the compression modulus of the soil layer.

For the case of a thin compressed soil layer, where the additional stress and the average compression modulus are fairly constant, equation (1) shows that the foundation settlement is proportional to the thickness of soil. Test data showed that the additional stress and the soil compression modulus at the tunnel substratum at a cross-section remained the same before and after the construction of a tunnel in soft soil. Even for different nearby sections, the change in additional stress of tunnel substratum soil is insignificant because the change in the longitudinal grade of the tunnel is small. However, the soil compression modulus may exhibit certain differences because of the geological inhomogeneity along the length of the tunnel. Thus, the amount of compression of substratum on different fracture surfaces follows a linear relationship between $S$ and $H / E_{S i}$.

b) The effect of aging (soil consolidation and creep)

Deformation of soft soil is actually a process of consolidation and creep simultaneously. According to the soil unidirectional consolidation theory:

$$
\left\{\begin{array}{l}
s_{t}=s \cdot\left(1-\frac{8}{\pi^{2}} e^{-\frac{\pi^{2}}{4} T_{v}}\right) \\
T_{v}=\frac{C_{v} t}{H^{2}}
\end{array}\right.
$$

In equation (2), final settlement of foundation $S$ is a theoretically determined value which is independent of time; $C_{v}$ is the coefficient of consolidation and is a constant; and $H$ is the thickness of compressible stratum and is a constant. The consolidation settlement of the foundation, St, is a function of time (t). However, the final settlement needs to be a theoretical value which is difficult to measure in reality. Also, huge complexity and uncertainty are involved in acquiring the value of consolidation coefficient and the thickness of compressible stratum. Thus, by simplifying and deducing equation (2), we can obtain:
$s_{t}=C \ln t+\delta$
In equation (3), $C=\frac{2 s C_{v}}{H^{2} e} \quad($ constant for a crosssection). Equation(3) proves that there is a linear relationship between the amount of consolidation settlement and $\ln t$ at time t.

2) Variation in groundwater level

According to Terzaghi's effective stress principle, soil compression after lowering the groundwater level to any depth $H$ can be obtained as:

$$
S=\int_{h}^{H} \frac{\Delta e}{1+e_{0}} d y=\int_{h}^{H} \frac{a_{v} \Delta p}{1+e_{0}} d y=\int_{h}^{H} \frac{a_{v}(y-h) \gamma_{w}}{1+e_{0}} d y
$$

where $e_{0}$ is the initial void ratio of soil; $\Delta e$ is the change in the void ratio; $a_{v}$ is the compressibility of soil; $\gamma_{w}$ is the pore water bulk density; $h$ is the initial groundwater level; and $H$ is the lowered groundwater level.

For a point on the soft soil substratum on the floor of the subway tunnel, each parameter in equation (4) can be considered as constant, except $H$. Hence, by using the integral method, we get:

$$
S=a_{1} H^{2}+a_{2} H+a_{3}
$$

where $a_{1}=\frac{a_{v} \gamma_{w}}{2\left(1+e_{0}\right)}, a_{2}=-\frac{a_{v} \gamma_{w} h}{1+e_{0}}, a_{3}=\frac{a_{v} \gamma_{w}}{2\left(1+e_{0}\right)} h^{2}$.

Equation (5) shows that soil subsidence is a second degree polynomial of groundwater level.

\section{B. Load Factors of Train Operation}

Under the action of train-induced dynamic load, soft soil has elastic deformation and plastic deformation. The former does not affect the post-construction settlement but the latter contributes to the tunnel settlement. By a preliminary study, the relationship between the soft soil deformation and the train load is derived ${ }^{[9]}$ as:

$$
E_{p}=a\left(\frac{q_{d}}{q_{f}}\right)^{m}\left(1+\frac{q_{s}}{q_{f}}\right)^{n} N^{b}
$$

where $E_{p}$ is cumulative plastic deformation. $N, q_{d}, q_{f}$, and $q_{s}$ are respectively the number of cyclic loading, the dynamic stress of traffic load $(k P a)$, the static destructive stress $(k P a)$, and the static deviator stress. Parameters $a, b, m, n$ are constants.

Equation (6) shows that soil parameters, static deviator stress and static destructive stress are constant at the same location. For subway tunnel, the passenger traffic and the traffic frequency are relatively stable on the section for non-transportation hub. Thus, the dynamic stress of traffic load in certain cases can also be regarded as a constant. Consequently, equation (6) can be adapted as follows:

$$
E_{p}=A B q_{d}^{m} N^{b}
$$


where $A=\frac{1}{q_{f}^{m}}, B=a\left(1+\frac{q_{s}}{q_{f}}\right)^{n}$ are constants.

\section{Effect of Tunnel Leakage}

Apart from the direct erosion of the loose soil surrounding a tunnel, leakage can create soil sediment flow paths, reduce pore water pressure, and increase soil effective stress. Consequently, soil gets compacted to cause subsidence, which in turn leads to the settlement of the subway tunnel. Hence, leakage is a serious threat to the safe operation of a tunnel structure.

According to the consolidation theory, The amount of soil consolidation, $S_{t}$, is calculated by storage rate, $S_{s}$, and the effective stress. The formula is as follows:

$$
S_{t}=m_{v} \Delta \sigma_{z} H=\frac{S_{s}}{\gamma_{w}} \Delta \sigma_{z} H=S_{s} \Delta h H
$$

where $\Delta h$ is the leakage caused by variation in water head and $H$ is the soil thickness. Since soil water storage and soil thickness are constant for a location, equation (8) shows that soil compression is directly proportional to water head.

\section{The influence of the external environmental factor}

The external environmental factors mainly include the construction load around the subway tunnel area, the traffic load of the ground, the regional land subsidence, and the regional atmospheric precipitation. Among all those factors, two main factors are the construction load around the subway tunnel area and the regional land subsidence. The other factors are minor and indirect; they have little effect on the subway tunnel settlement and can be ignored.

1) The construction load around the subway tunnel area

The effect of the variation in construction load around the subway tunnel area to the settlement of a point is dependent only on the load. Thus, the settlement maintains a linear relationship with the vertical stress as:

$$
s=a F
$$

where $s$ is the point of settlement, $a$ is a coefficient, and $F$ is the construction load.

\section{2) The regional land subsidence}

A deep multilayer soil generates compressed deformation under the influence of various factors, which cause regional land subsidence. Typically, a subway tunnel is in shallow ground, and undergoes settlement corresponding to the ground subsidence. Therefore, the settlement of subway tunnel structure and regional land subsidence follow a linear relationship.

III. VARIATION CHARACTERISTICS OF THE INFLUENCE FACTORS IN SETTLEMENT OF SUBWAY TUNNEL IN SOFT SOIL

Table I presents the influences of the different factors discussed in section II to the long term settlement of a subway tunnel in the lateral and longitudinal directions.

As Table 1 shows, for the same period of monitoring, all point (i.e. soil consolidation and creep) agreement. The other factors are not identical in addition to the same section of train operation load, For the same monitoring point, the thickness of tunnel floor bottom layer remains long-term basic constant, which is a vertical constant and the other factors of each are different.

\begin{tabular}{|c|c|c|c|c|}
\hline No. & Factor & Lateral & Longitudinal & $\begin{array}{c}\text { variation } \\
\text { characteristics }\end{array}$ \\
\hline 1 & $\begin{array}{l}\text { Substratum } \\
\text { soil layer } \\
\text { distribution } \\
\text { on the } \\
\text { baseboard of } \\
\text { a tunnel }\end{array}$ & $\begin{array}{c}\text { per issue } \\
\text { the } \\
\text { same }\end{array}$ & variable & $\begin{array}{c}\text { longitudinal } \\
\text { variation }\end{array}$ \\
\hline 2 & $\begin{array}{c}\text { Soil } \\
\text { Consolidation } \\
\text { and Creep }\end{array}$ & $\begin{array}{l}\text { per issue } \\
\text { the } \\
\text { difference }\end{array}$ & variable & $\begin{array}{c}\text { lateral } \\
\text { variation }\end{array}$ \\
\hline 3 & $\begin{array}{c}\text { Groundwater } \\
\text { Level }\end{array}$ & $\begin{array}{l}\text { per issue } \\
\text { the } \\
\text { difference }\end{array}$ & $\begin{array}{c}\text { Each point } \\
\text { the difference }\end{array}$ & $\begin{array}{l}\text { bidirectional } \\
\text { variation } \\
\text { and dominant } \\
\text { lateral } \\
\text { variation }\end{array}$ \\
\hline 4 & Train Load & $\begin{array}{c}\text { per issue } \\
\text { the } \\
\text { difference }\end{array}$ & $\begin{array}{c}\text { Each point } \\
\text { the same of a } \\
\text { section }\end{array}$ & $\begin{array}{c}\text { lateral } \\
\text { variation }\end{array}$ \\
\hline 5 & $\begin{array}{l}\text { Tunnel } \\
\text { leakage }\end{array}$ & $\begin{array}{l}\text { per issue } \\
\text { the } \\
\text { difference }\end{array}$ & $\begin{array}{l}\text { Each point } \\
\text { the difference }\end{array}$ & $\begin{array}{c}\text { bidirectional } \\
\text { variation }\end{array}$ \\
\hline 6 & $\begin{array}{l}\text { Regional } \\
\text { Building } \\
\text { Load }\end{array}$ & $\begin{array}{l}\text { per issue } \\
\text { the } \\
\text { difference }\end{array}$ & $\begin{array}{c}\text { Each point } \\
\text { the difference }\end{array}$ & $\begin{array}{l}\text { bidirectional } \\
\text { variation } \\
\text { and change } \\
\text { shortly } \\
\end{array}$ \\
\hline 7 & $\begin{array}{c}\text { Regional } \\
\text { Land } \\
\text { Subsidence }\end{array}$ & $\begin{array}{l}\text { per issue } \\
\text { the } \\
\text { difference }\end{array}$ & $\begin{array}{l}\text { Each point } \\
\text { the difference }\end{array}$ & $\begin{array}{l}\text { bidirectional } \\
\text { variation } \\
\text { and lateral } \\
\text { change greatly }\end{array}$ \\
\hline
\end{tabular}

TABLE I. THE CONTRAST TABLE OF VARIATION CHARACTERISTICS

\section{ANALYSIS OF INFLUENCED DEGREE OF SUBWAY TUNNEL SETTLEMENT}

In terms of the influence in the settlement process and its nature, the influencing factors are so many that there must be some correlation with each other and overlap between the information they carry. Thus, the principal component analysis is applied in this study [10-11]. Given the variation of settlement factors, the settlement factors can be discussed and analyzed from two aspects as, horizontal and vertical. The analysis can also be performed in the same way for the measurement at the same point at different periods, and measurement at different points at the same period.

\section{A. Horizontal Analysis}

Under the circumstance that the thickness of soil substratum on the floor of the subway remains essentially constant, the same point was considered at different measurement periods. The change in each factor at different measurement period was analyzed to estimate the influence of individual factor to the degree of settlement. Thus, the analysis included monitoring data from 5 measuring points of a subway tunnel for 11 consecutive periods (over 3 years). Since the thickness of soil substratum cannot be included into principal component analysis at each point, this study took the aging, the square of groundwater level, groundwater level, train load, and cumulative ground subsidence into consideration. The contributions of different factors at different points are listed in Table II . 


\begin{tabular}{|c|c|c|c|c|c|}
\hline $\begin{array}{c}\text { Measuremen } \\
\text { t Period }\end{array}$ & $\begin{array}{c}\text { Thickness } \\
\text { of Soil } \\
\text { Substratu } \\
\mathbf{m}\end{array}$ & \multicolumn{2}{|c|}{\begin{tabular}{c}
\multicolumn{2}{|c|}{ Groundwater } \\
Level
\end{tabular}} & $\begin{array}{c}\text { Trai } \\
\mathbf{n} \\
\text { Load }\end{array}$ & $\begin{array}{c}\text { Cumulative } \\
\text { Ground } \\
\text { Subsidence }\end{array}$ \\
\cline { 2 - 6 } & $H_{1} / E_{S}$ & $H_{2}^{2}$ & $H_{2}$ & $N^{b^{*}}$ & $H_{4}$ \\
\hline 2007.3 & 59.998 & $\begin{array}{c}34.78 \\
9\end{array}$ & 4.925 & 0.288 & $2.34 \mathrm{E}-015$ \\
\hline 2007.9 & 61.798 & $\begin{array}{c}33.71 \\
6\end{array}$ & 4.213 & 0.273 & $1.49 \mathrm{E}-015$ \\
\hline 2008.3 & 62.290 & $\begin{array}{c}33.24 \\
5\end{array}$ & 4.145 & 0.320 & $1.03 \mathrm{E}-015$ \\
\hline 2008.9 & 61.947 & $\begin{array}{c}33.46 \\
8\end{array}$ & 4.228 & 0.356 & $1.26 \mathrm{E}-015$ \\
\hline 2009.3 & 61.645 & $\begin{array}{c}33.63 \\
0\end{array}$ & 4.306 & 0.419 & $3.42 \mathrm{E}-015$ \\
\hline 2009.9 & 62.415 & $\begin{array}{c}32.93 \\
8\end{array}$ & 4.219 & 0.428 & $4.32 \mathrm{E}-015$ \\
\hline
\end{tabular}

TABLE II. THE DEGREE OF CONTRIBUTION OF DIFFERENT FACTORS AT THE TYPICAL MEASUREMENT POINTS（UNIT: \%)

It can be concluded from Table 2 that the aging (soil consolidation and creep) is the most influencing factor; the effect of groundwater level is relatively small and the remaining factors have negligible effect.

\section{B. Vertical analysis}

Under the circumstance that the aging is essentially constant to all the points at a particular measurement period, analysis was performed for the other factors to estimate the degree of settlement. Since the aging cannot be included into the principal component analysis, this study took the thickness of soil substratum, the square of groundwater level, groundwater level, train load and cumulative ground subsidence into consideration. The contributions of different factors at different periods are listed in TableIII.

TABLE III. THE DEGREE OF CONTRIBUTION OF DIFFERENT FACTORS AT DIFFERENT MEASUREMENT PERIODS（UNIT: \%)

\begin{tabular}{|c|c|c|c|c|c|}
\hline \multirow{2}{*}{$\begin{array}{c}\text { Measuring } \\
\text { point }\end{array}$} & Aging & \multicolumn{2}{|c|}{$\begin{array}{c}\text { Groundwater } \\
\text { Level }\end{array}$} & $\begin{array}{c}\text { Train } \\
\text { Load }\end{array}$ & $\begin{array}{c}\text { Cumulative } \\
\text { Ground } \\
\text { Subsidence }\end{array}$ \\
\cline { 2 - 6 } & $\ln t$ & $H_{2}^{2}$ & $H_{2}$ & $N^{b^{*}}$ & $H_{4}$ \\
\hline $\mathrm{K} 1+033$ & 83.154 & 16.758 & 0.069 & 0.016 & 0.003 \\
\hline $\mathrm{K} 1+090$ & 83.936 & 15.961 & 0.073 & 0.028 & 0.003 \\
\hline $\mathrm{K} 1+337$ & 82.576 & 17.345 & 0.060 & 0.017 & 0.002 \\
\hline $\mathrm{K} 1+470$ & 74.187 & 25.600 & 0.172 & 0.033 & 0.008 \\
\hline $\mathrm{K} 1+641$ & 62.178 & 37.588 & 0.180 & 0.032 & 0.022 \\
\hline
\end{tabular}

TableIII shows that the thickness of soil substratum remains the main factor to affect the settlement in the transverse direction. The effect of groundwater level is the second most influencing factor. The effect of train load on the settlement is relatively small and that of cumulative ground subsidence is negligible.

In the longitudinal direction too, the thickness of soil substratum on the floor of the subway is the most influencing factor, and the remaining factors have similar orders of influence as with the transverse direction. Over the time, the impact of various factors on the tunnel gradually dispersed. On the one hand, the influence of the main factors, such as the thickness of soil substratum and the groundwater level, remains unchanged. On the other hand, the influence of the rest of the factors gradually increases.

\section{CONCLUSIONS}

This study identified seven different factors that influence the settlement of subway tunnel. A mathematical model was developed based on the principal component analysis method to investigate the degree of influence of the factors both qualitatively and quantitatively. The analysis results were interpreted from the two aspects, namely, horizontal (time) and vertical (space). The following conclusions are made:

- In overall, tunnel floor bottom layer thickness and soil consolidation and creep are the main factors to influence the settlement of a subway tunnel. Second most influence was occurred due to underground water level. The influence of train loads and the accumulated settlement is relatively small.

- For a single measurement point, aging (soil consolidation and creep) is the main influencing factor; the influence of underground water level is fairly small, and the influences of train loads and the accumulated settlement are negligible.

- For a single measurement period, tunnel floor bottom layer thickness is the main influencing factor; the second influencing factor is the underground water level; the third and the fourth are respectively the train loads and the accumulated settlement.

- With an increase in service life, the influence of the thickness of tunnel floor bottom layer shows a weak fluctuating trend. The position of its main factors have an increasing trend, the influence of underground water level has a similar change, but changes of train loads and the accumulated settlement are more and more obvious.

- The principal component analysis method for analysis of the causes of settlement in service life of subway tunnel in soft soil has a good applicability. It can meet the requirements of qualitative and quantitative analysis of the degree of influence of various factors. The method is able to qualitatively and quantitatively analyze the degree of influence of different factors from the two aspects, namely, horizontal and vertical.

\section{ACKNOWLEDGMENT}

This project was supported by Hohai University fundamental research funds for the Central Universities project(2012B01714).

\section{REFERENCES}

[1] Jiwei Chen,Longxi Zhan. Regularity analysis and deformation measurement of Shanghai Metro Line $1[\mathrm{~J}]$. Urban Geology,2000,(2):51-56.

[2] Rulu Wang,Xianhao Zhou,Yongliang Yu. Problems and Solutions of Shanghai Metro Monitoring recently[A]. The Fourteenth Symposium of Professional Committee of the underground railroad, 
Institute of tunnel and underground engineering, China Civil Engineering Society [C].2001:239-242.

[3] Guanlong Huang,Ming Wei,Aiming Han,Guoxiong Mei. Analysis on the subsidence of tunnel foundation in Nanjing Yangtze River valley flat $[\mathrm{J}]$. Engineering Geology and Hydrogeology for civil engineering majors,2006,(3):112-116.

[4] Yongguo Lin, Shaoming Liao,Guobing Liu. A Discussion of the Factors Effecting on Longitudinal Deformation of Subway Tunnel[J]. Underground Space,2000,20(4):264-290.

[5] Rulu Wang. Factors Influencing Deformation of Shanghai Soft Soil MetroTunnel and Deformation Analysis [J]. Substructure Work and Tunnel,2009,(1):1-6.

[6] Guanlong Huang,Ming Wei,Aiming Han,Guoxiong Mei. Analysis on the subsidence of tunnel foundation in Nanjing Yangtze River valley flat $[\mathrm{J}]$. Engineering Geology and Hydrogeology for civil engineering majors,2006,(3):112-116.

[7] MingLiu,Maosong Huang,Jinjun Li.Long-term Settlement of Saturated Soft Clay under Subway Loading[J].Chinese Journal of Underground Space and Engineering, 2006, 2(5): 813-817.

[8] Mengxi Zhang.Principle of Soil Mechanics[M].Wuhan: Press of Huazhong University of Science and Technology,2007.

[9] Cha,i J. and Miura, N. Traffic-load-induced permanent deformation of road on soft subsoil [J]. Journal of geotechnical and geoenvironmental, 2002: 907-915.

[10] Xiaoqun He. Multivariate statistical analysis (The second edition) [M].Beijing: Press of Renmin University of China, 2008.

[11] Sun Yifei,Liu Hanlong, Yang Gui,Xiao Yang. Formulation of cross-anisotropic failure criterion for soils[J].Water Science and Engineering, 2013,(6):456-468. 